\title{
Developing a Standardized and Reusable Method to Link Distributed Health Plan Databases to the National Death Index: Methods Development Study Protocol
}

Candace C Fuller ${ }^{1}$, MPH, PhD; Wei Hua ${ }^{2}$, MSc, MHS, MD, PhD; Charles E Leonard ${ }^{3}$, PharmD, MSCE; Andrew Mosholder $^{2}$, MD, MPH; Ryan Carnahan ${ }^{4}$, PharmD, MS; Sarah Dutcher ${ }^{2}$, PhD, MS; Katelyn King ${ }^{1}$, BA; Andrew B Petrone $^{1}$, MPH; Robert Rosofsky ${ }^{5}$, MA; Laura A Shockro ${ }^{1}$, BA; Jessica Young ${ }^{1}$, PhD; Jea Young Min ${ }^{6}$, PharmD, MPH, PhD; Ingrid Binswanger ${ }^{7}, \mathrm{MD}, \mathrm{MPH}, \mathrm{MS}$; Denise Boudreau ${ }^{8}, \mathrm{RPh}, \mathrm{PhD}$, MS; Marie R Griffin ${ }^{6}, \mathrm{MD}, \mathrm{MPH}$; Margaret A Adgent ${ }^{6}$, MSPH, PhD; Jennifer Kuntz ${ }^{9}$, MS, PhD; Cheryl McMahill-Walraven ${ }^{10}$, MSW, PhD; Pamala A Pawloski ${ }^{11}$, PharmD; Robert Ball ${ }^{2}, \mathrm{MD}, \mathrm{MPH}, \mathrm{ScM}$; Sengwee Toh ${ }^{1}, \mathrm{ScD}$

${ }^{1}$ Department of Population Medicine, Harvard Pilgrim Health Care Institute, Harvard Medical School, Boston, MA, United States

${ }^{2}$ Office of Surveillance and Epidemiology, Center for Drug Evaluation and Research, Food and Drug Administration, Silver Spring, MD, United States

${ }^{3}$ Center for Pharmacoepidemiology Research and Training, Department of Biostatistics, Epidemiology, and Informatics Perelman School of Medicine, University of Pennsylvania, Philadelphia, PA, United States

${ }^{4}$ University of Iowa, College of Public Health, Iowa City, IA, United States

${ }^{5}$ Health Information Systems Consulting, Milton, MA, United States

${ }^{6}$ Vanderbilt University, Nashville, TN, United States

${ }^{7}$ Kaiser Permanente Colorado, Aurora, CO, United States

${ }^{8}$ Kaiser Permanente Washington Health Research Institute and University of Washington, Seattle, WA, United States

${ }^{9}$ Kaiser Permanente Northwest, Portland, OR, United States

${ }^{10}$ Aetna, a CVS Health company, Blue Bell, PA, United States

${ }^{11}$ HealthPartners Institute, Bloomington, MN, United States

\section{Corresponding Author:}

Candace C Fuller, MPH, PhD

Department of Population Medicine

Harvard Pilgrim Health Care Institute

Harvard Medical School

401 Park Drive, Suite 401 East

Boston, MA, 02215

United States

Phone: 16178674867

Email: Candace Fuller@harvardpilgrim.org

\section{Abstract}

Background: Certain medications may increase the risk of death or death from specific causes (eg, sudden cardiac death), but these risks may not be identified in premarket randomized trials. Having the capacity to examine death in postmarket safety surveillance activities is important to the US Food and Drug Administration's (FDA) mission to protect public health. Distributed networks of electronic health plan databases used by the FDA to conduct multicenter research or medical product safety surveillance studies often do not systematically include death or cause-of-death information.

Objective: This study aims to develop reusable, generalizable methods for linking multiple health plan databases with the Centers for Disease Control and Prevention's National Death Index Plus (NDI+) data.

Methods: We will develop efficient administrative workflows to facilitate multicenter institutional review board (IRB) review and approval within a distributed network of 6 health plans. The study will create a distributed NDI+ linkage process that avoids sharing of identifiable patient information between health plans or with a central coordinating center. We will develop standardized criteria for selecting and retaining NDI+ matches and methods for harmonizing linked information across multiple health plans. We will test our processes within a use case comprising users and nonusers of antiarrhythmic medications. 
Results: We will use the linked health plan and NDI+ data sets to estimate the incidences and incidence rates of mortality and specific causes of death within the study use case and compare the results with reported estimates. These comparisons provide an opportunity to assess the performance of the developed NDI+ linkage approach and lessons for future studies requiring NDI+ linkage in distributed database settings. This study is approved by the IRB at Harvard Pilgrim Health Care in Boston, MA. Results will be presented to the FDA at academic conferences and published in peer-reviewed journals.

Conclusions: This study will develop and test a reusable distributed NDI+ linkage approach with the goal of providing tested NDI+ linkage methods for use in future studies within distributed data networks. Having standardized and reusable methods for systematically obtaining death and cause-of-death information from NDI+ would enhance the FDA's ability to assess mortality-related safety questions in the postmarket, real-world setting.

International Registered Report Identifier (IRRID)： DERR1-10.2196/21811

(JMIR Res Protoc 2020;9(11):e21811) doi: 10.2196/21811

\section{KEYWORDS}

National Death Index; data linkage; all-cause mortality; cause specific mortality; distributed analysis; multisite research

\section{Introduction}

\section{Public Health Significance and Study Motivation}

Certain medications may increase the risk of death and specific causes of death (eg, sudden cardiac death [SCD]), but these risks may not be identified in premarket randomized controlled trials owing to the relatively small sample sizes and the highly selected patient populations in these trials. The capacity to examine the risk of death in postmarket safety surveillance activities is an important part of the US Food and Drug Administration's (FDA) mission to protect public health. Although the FDA Adverse Event Reporting System (FAERS) [1] identifies drug safety signals [2] and is vital to this mission [3], FAERS has a number of known limitations. Similar to most spontaneous reporting systems that rely primarily on voluntarily reported adverse events, FAERS is susceptible to underreporting, variable data quality, lack of denominator information, and frequent absence of details necessary to evaluate clinical events and associations with a specific medication [4-6].

Other components of the FDA's postmarket medical product safety surveillance system complement FAERS in many ways but often do not systematically capture death or cause-of-death information. For example, the FDA's Sentinel System [7,8] includes a distributed network of electronic health plan databases. The health plans that participate in the Sentinel System or other multicenter research networks routinely capture data on in-hospital deaths and medically attended deaths but often do not have complete capture of out-of-hospital deaths or cause-of-death information. Although some health plans perform routine or ad hoc linkages with local or state death registries or Social Security Administration (SSA) data to address these data gaps, such linkages are often specific to a particular study or site.

In addition, some multicenter research networks use a distributed data approach in which individual study sites or health plans maintain physical and operational control over their electronic health data behind their respective firewalls. A distributed network approach promotes data sharing by protecting patient privacy, data security, and proprietary interests [9-12]. The development of a systematic method to link distributed databases to a data source that includes both death and cause-of-death information, such as the National Death Index (NDI), would enhance the FDA's ability to answer mortality-related safety questions in the postmarket setting.

\section{NDI and Cause-of-Death Information}

The NDI, a self-supporting service within the National Center for Health Statistics (NCHS) of the Centers for Disease Control and Prevention, is a centralized database of death record information compiled from the vital statistics offices of states and other jurisdictions. The NDI provides death information including death date and death certificate number (referred to as the NDI data) and cause of death from death certificates (referred to as NDI Plus or NDI+ data) upon request [13]. Although the SSA also provides the fact of death, it does not provide cause-of-death information, and a 2011 determination by the SSA that data submitted electronically by states cannot be publicly shared in the SSA death master file has since limited its coverage [14].

The limitations of the cause-of-death information derived from death certificates, the foundation of state death records, and subsequent NDI information have been well described [15]. In brief, although efforts have been made to improve the completeness and accuracy of cause-of-death reporting in the United States, the cause-of-death information in the death certificate ultimately represents medical opinions. The certifier (eg, attending physician, medical examiner, coroner) provides a clinical judgment informed by their training, knowledge of medicine, and available medical history of the decedent [16]. Certifier requirements (eg, coroner or medical examiner) can also vary according to state laws [17]. Variation in all of these elements can lead to inaccurate documentation by the certifier, and studies have found that causes of death listed on the death certificates, and subsequently coded in NDI+ data, may be misclassified by $16 \%$ to $40 \%$, depending on the cause $[18,19]$. Misclassification may increase when the death is sudden and unobserved [20,21] and also when more narrowly defined causes of death are listed [22]. Errors introduced during translation of the causes of death on death certificates to the International Classification of Diseases, 10th Revision (ICD-10) codes are much less common [23,24].

Despite the known limitations of death certificate data, researchers have used these data to examine national death data 
trends and changes in causes of death over time [22,25,26] and have used death certificate data with other data sources to more accurately define specific causes of death, such as SCD [27]. Notwithstanding the above mentioned limitations, the NDI is currently the only complete national source of death and cause-of-death information accessible to large-scale population-based epidemiologic studies in the United States.

\section{Primary and Secondary Objective of the Study}

\section{Overview of the Study Objectives}

The primary objective of this study is to develop reusable administrative and technical processes for linking multiple health plan databases with NDI+ data to allow the FDA to assess death and specific causes of death as outcomes in medical product safety and effectiveness studies in distributed networks of electronic health plan databases. We will pilot the developed approach through a use case comprising antiarrhythmic medication users and nonusers. The outcomes of interest in the use case are all-cause mortality and SCD, but cardiovascular death may also be examined if it is feasible within the study timeline.

The secondary objectives focus on using the linked health plan and NDI+ data to estimate the incidences and incidence rates of mortality and specific causes of death within the use case and comparing them with estimates reported in the literature. Examining the incidences and incidence rates of mortality and death from specific causes within the use case will provide an opportunity to assess the performance of the workflows and processes developed under the primary objectives.

\section{Primary Objectives}

1. Develop and pilot an administrative workflow that facilitates efficient, coordinated, multicenter institutional review board
(IRB) review and approval for linking health plan data with $\mathrm{NDI}+$ data.

2. Create and pilot a distributed technical process for linking health plan and NDI+ data that:

- uniformly identifies records to be submitted to the NDI from each health plan

- avoids sharing of identifiable patient information between participating health plans or with the coordinating center and allows health plans to work directly with the NDI

- uses standardized criteria to select and retain confirmed or best match from linked NDI+ data across multiple health plans

- harmonizes linked information across multiple health plans by saving NDI+ data in a standardized format

\section{Secondary Objectives}

The secondary objectives are as follows:

1. Estimate the incidences and incidence rates of all-cause mortality, SCD, and potentially cardiovascular death within a high-risk use case cohort (ie, individuals using antiarrhythmic medications) and an average-risk cohort (ie, individuals not on antiarrhythmic medications).

2. Assess the performance of the developed workflows and processes for linking health plan and NDI+ data by examining the incidences and incidence rates of all-cause mortality, SCD, and potentially cardiovascular death within the use case cohorts, and comparing them with estimates previously reported in the literature.

Figure 1 provides an overview of the questions this study will address and anticipated contributions.

Figure 1. Overview of study questions and anticipated contributions. NDI: National Death Index; IRB: Institutional Review Board; PHI: Protected Health Information.

\section{Study questions and anticipated contributions}

Study questions and anticipated contributions
How to achieve administrative permissions across multiple health plans so linkage to the National Death
Index (NDI) can occur? The study will create:
- A tested process for working with a central IRB for multi-center studies requiring death or cause of death
- Recommendations for completing successful NDI application




\section{Methods}

\section{Use Case and Rationale}

For this study, we chose antiarrhythmic medications as the use case. The arrhythmogenicity of antiarrhythmic medications is well known, and several antiarrhythmic medications are known to be associated with elevated risks of all-cause mortality and SCD [28-30]. SCD associated with arrest, generally defined as the sudden cessation of heart function, is a major cause of mortality and a major public health concern. Ventricular fibrillation is often associated with SCD and is a pulseless arrhythmia with irregular and chaotic electrical activity and ventricular contraction in which the heart immediately loses its ability to pump [31]. Ventricular fibrillation is the initial electrocardiogram rhythm in $75 \%$ of outpatient cases of SCD [32]. Torsade de Pointes is a specific form of polymorphic ventricular tachycardia that if rapid or prolonged can lead to ventricular fibrillation and SCD [33].

There are approximately 20 cardiovascular medications and well over 100 noncardiovascular medications suspected of causing SCD, ventricular fibrillation, or Torsade de Pointes [28]. For example, although class III antiarrhythmic medications are used to treat atrial or ventricular arrhythmias, they prolong repolarization and cardiac refractoriness and can increase an individual's propensity for Torsade de Pointes [34]. In addition, individuals with arrhythmias are at a high risk of death and SCD. Therefore, we expect all-cause mortality as well as SCD to be more common in antiarrhythmic medication users than in a cohort not exposed to these medications. As the incidences of mortality and SCD in the US population are well described [35-37], identification of a cohort at average risk of these outcomes will provide an efficient reference point for antiarrhythmic medication users and an opportunity to assess the performance or validity of the linkage to NDI+ data.

\section{Participating Organizations}

This project will be led and coordinated by the Harvard Pilgrim Health Care Institute (HPHCI), which will work closely with the FDA and participating health plans in all aspects of the project. A total of 6 health plans-Aetna, a CVS Health company; HealthPartners Institute; Kaiser Permanente Colorado; Kaiser Permanente Northwest; Kaiser Permanente Washington; and Vanderbilt University (which provides access to Tennessee Medicaid data)—will participate in this project. They represent a diverse group of health plans, including national insurers, regional health plans, and integrated delivery systems, and cover both commercial and public insurance programs. Although the project will leverage the Sentinel infrastructure and be built on the successful collaboration among participating institutions, it will be conducted outside of the Sentinel Initiative and will be relevant to other distributed data networks. The project is a research activity subject to the Office for Human Research Protections regulations, following the 45 Code of Federal Regulations 46 [38] on the protection of human subjects, and will undergo IRB review.

\section{Development of Multisite Administrative Workflows to Support Linkage to NDI+ Data}

\section{Overview of the Administrative Workflows}

This project will develop reusable and flexible administrative workflows required to support simultaneous linkage of multiple health plan databases with NDI+ data. As the lead project site and coordinating center, the HPHCI will develop and facilitate administrative processes for IRB workflow as well as submission of the master NDI application on behalf of the participating health plans. The HPHCI will lead the development of the NDI application package, coordinate review by participating health plans and the FDA as well as the execution of legal agreements (as necessary), and will submit the master NDI application that will include IRB documents and approvals.

The HPHCI will review, consider, and accommodate the requirements of institutions involved in this project to ensure that the developed workflows for NDI and IRB application review and approval are flexible enough to be reused in future studies. This may require review and response to any of the following: health plan institutional requirements, FDA requirements, relevant federal requirements (eg, revised Common Rule [39] and other requirements), relevant state or local jurisdiction requirements (eg, laws concerning death data), institutional IRB requirements, or NCHS/NDI requirements. For example, preliminary work with participating health plans suggested the need to consider any state or local laws pertaining to death data within project workflows. Balancing such requirements as well as any other identified prerequisites or constraints will be a key focus of the developed multisite administrative workflow. In the following paragraphs, we describe our anticipated processes for implementing coordinated multisite, central IRB review and approval, as well as multisite NDI application review and approval.

\section{IRB Application Workflow}

The revised Common Rule requires the use of a central IRB for multisite research, with certain exceptions (82 Fed. Reg. at 7265 [final rule §.114]) [39]. In addition, the NDI currently requires all studies requesting NDI+ data to undergo IRB review. This project will develop and pilot an administrative workflow that facilitates efficient, coordinated, multicenter IRB review and approval for linking health plan data with NDI+ data in accordance with the revised Common Rule.

The IRB at Harvard Pilgrim Health Care, the parent organization of the HPHCI, is responsible for managing and supporting scientific and ethical review of research studies submitted by the HPHCI. The HPHC IRB also enters into reliance agreements for multisite studies as a reviewing IRB and a relying IRB. The HPHC IRB holds a Federalwide Assurance (FWA) with the US Department of Health and Human Services [FWA00000100] and thus is compliant with human subjects regulations within 45 Code of Federal Regulations 46 [38,40]. As the lead study institution, the HPHCI will aim to have the HPHC IRB serve as the IRB of record, with all participating sites ceding their IRB review to the HPHC IRB. However, if the use of a single IRB entity is determined not to be feasible or acceptable to the NCHS, the NDI board, or participating health plans, the HPHCI 
will work with each participating health plan to attain IRB approval.

The study team will describe the necessary administrative workflow processes and highlight any encountered governance challenges (eg, local institutional policies or procedures) and potential solutions. Furthermore, the study team will address any complications with individual study sites obtaining approval to cede to the HPHC IRB in the final developed workflow. The anticipated central IRB workflow is as follows:

1. The HPHCI will submit an IRB application to the HPHC IRB and obtain HPHC IRB approval for the study. The HPHCI and collaborating health plans to cede review by initiating and executing reliance agreements with respective health plan IRB(s). Reliance agreements must be in place for local health plan IRBs to cede review and for the HPHC IRB to serve as the lead reviewing IRB. We anticipate the cede process will proceed as follows:

- The HPHCI will provide the HPHC IRB application and approval to participating health plans for review. The HPHCI will work with health plans to address any concerns or amendments needed to satisfy approval to cede to the HPHC IRB. Individual health plan-specific policies and procedures may apply and will be documented.

- Participating health plans will prepare all necessary cede request documents required by site $\operatorname{IRB}(\mathrm{s})$ and the HPHC IRB. Health plans will submit a cede request to the HPHC IRB.

- The HPHC IRB will review the submitted cede requests and may require additional health plan-specific materials in determining approval to accept the request (eg, documentation of human subjects training from key personnel).

- The lead HPHC IRB and the IRB(s) at participating health plans will fully execute reliance agreements, formally known as IRB authorization agreements, to officially confirm the HPHC IRB as the lead reviewing IRB of record for the study.

2. Following the completed cede process, the HPHC IRB will be responsible for continuing review as well as amendment and reviewing of any unanticipated problems. Participating health plans will be responsible for timely communication and reporting to the HPHC IRB for any unanticipated problems encountered at their site for this study.

The anticipated central IRB workflow process will be updated as new procedures or processes are encountered. A final recommended IRB workflow will be created after the process is piloted and will include lessons learned, requirements for each involved institution (eg, FDA, HPHCI, participating health plans), relevant flowcharts, and recommendations for future studies.

\section{NDI Application Workflow}

The HPHCI will lead the NDI application development and subsequent application review by the FDA and the health plans before submission of the final application package to the NDI. The published guidelines for obtaining NDI application approval by the NDI board will inform the developed workflow [41]. The HPHCI will also work with staff at the NDI to ensure all requirements are met in accordance with the NDI guidelines. Process development may be iterative, with the NDI providing guidelines and the HPHCI subsequently working with health plans and the FDA to ensure guidelines are met. Preliminary work has identified the need for specific process development in IRB approval for the protection of human subjects, final disposition of identifiable data, and NDI-required agreements.

The HPHCI will document lessons learned from piloting the administrative workflows that will inform the development of a flexible and reusable process intended to guide future studies. The HPHCI will review the NDI and IRB stipulations encountered during this study and ensure appropriate processes and guidelines are built to accommodate them. As the NDI and IRB administrative workflows are interdependent, we will use an iterative process outlining and updating the IRB and NDI administrative workflows as new stipulations or requirements are encountered. Thus, the overall administrative workflow will include recommendations for IRB and NDI application development for use in future studies.

\section{Development of Distributed Process for Linkage Between Health Plan and NDI+ Data}

\section{Overview of the Distributed Linkage Process}

The HPHCI, in collaboration with the FDA and participating health plans, will develop a distributed linkage process that allows health plans to work directly with the NDI to eliminate sharing of identifiable patient information between participating health plans or with the coordinating center. The HPHCI will develop the distributed NDI+ data linkage process with input from the participating health plans and pilot the process within the study use case. Health plans will identify and submit individuals meeting specific criteria within the use case cohorts to the NDI for matching. The HPHCI will also work with each participating health plan to develop and ensure a standardized NDI+ data linkage process across databases. Figure 2 provides a high-level overview of the anticipated distributed process for linkage between health plan data and NDI+ data.

Piloting the process with the study use case will elucidate adjustments that could be made to improve efficiency and provide flexible options for future studies. We will summarize practical lessons learned from the participating health plans and the NDI. Although the NDI User's Guide [42] describes the general process for NDI+ data linkage within a single site, the developed technical workflow will need to enable linkage to NDI+ data at multiple study sites. Accomplishing timely and standardized linkage to NDI+ data across multiple sites requires defining and implementing a set of NDI submission criteria, ensuring adequate file preparation and quality control processes across sites, standardizing the selection and retention of NDI matches, and storing information retrieved from the NDI in standardized table(s) so that study analyses can be implemented. We anticipate the following tasks will be required to build a distributed process for linkage between health plan and NDI+ data. 
Figure 2. Overview of the distributed National Death Index data linkage process. NDI: National Death Index; PHI: Protected Health Information.

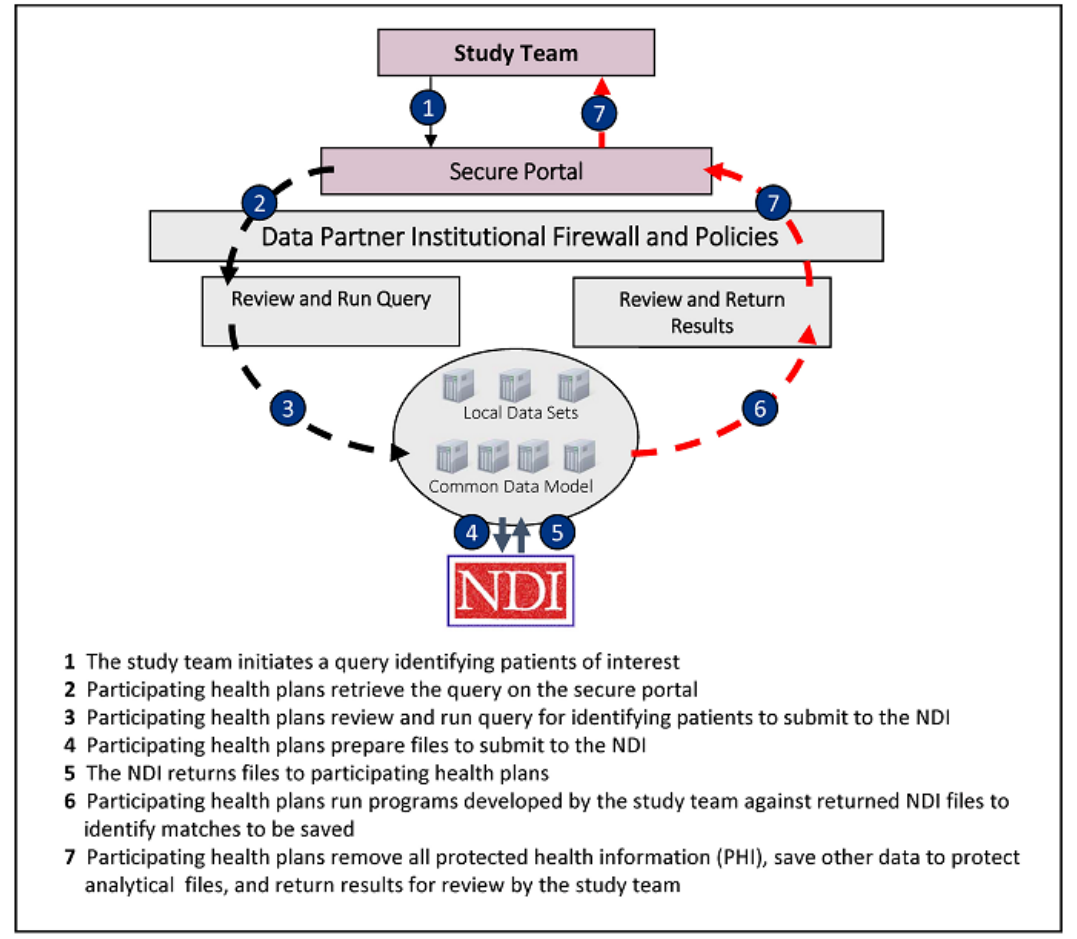

\section{Defining NDI Submission Criteria}

This project will develop, pilot, and recommend case identification and NDI submission criteria for future multicenter studies. Multimedia Appendix 1 includes the case identification and NDI submission criteria this project will use to determine which individuals will be initially selected for sending to the NDI, thereby obtaining death and cause-of-death information. We anticipate submitting patients with deaths recorded in health plan data or patients with potential deaths to the NDI for linkage. We will define potential death as health plan disenrollment between cohort entry and cohort exit plus 365 days, without subsequent reenrollment or medical utilization $>60$ days after disenrollment. It is possible that these NDI submission criteria will be refined or redesigned as they are piloted within the study use case. We will describe the final developed case identification and NDI submission algorithm and provide this information for use in future studies.

\section{Preparing Files for Submission to the NDI}

The NDI publishes information that health plans must provide to conduct an NDI+ data search as well as the required file structures in their NDI User's Guide [42]. Health plans will need to access these required data elements from their source systems and transmit complete records to the NDI for matching. To ensure that files submitted to the NDI are of sufficient completeness, the HPHCI will develop distributed programs for local execution by the health plans to identify any potential data or formatting issues. Any lessons learned during these file preparation and quality control processes will be documented for future use and incorporation into the technical workflow.

\section{Standardizing NDI+ Data Linkage Across Multiple Health Plan Databases}

After files intended for submission to the NDI have been checked to ensure sufficient completeness and quality, each health plan will submit their selected health plan members for matching directly with NDI+ data. Health plan data files will be transferred to the NCHS via either password-protected encrypted CDs or a secure file transfer protocol site, according to the health plan and NCHS or NDI requirements. When NDI staff return data files directly to health plans, health plans will load the returned files to their computer servers behind their firewalls. These data sets will remain behind their firewalls and will not be shared with the HPHCI, the FDA, or other health plans. We will summarize the processes, challenges, and requirements in the technical workflow.

\section{Selecting and Retaining the Best NDI Match}

When the NDI performs matching, multiple possible matches for each individual submitted may be provided within the NDI-returned data files. The NDI User's Guide [42] provides guidelines for selection and retention of NDI matches, from among multiple possible matches for each individual submitted. This requires researchers to assess the quality of each possible NDI record match listed and determine which possible matches are best matches. The NDI recommends a multistep process when determining the best match among possible multiple matches, including using the NDI-provided probabilistic matching scores to distinguish true matches from false matches. The HPHCI, guided by the principles within the NDI User's Guide [42], will develop a standardized process for ascertaining and keeping confirmed or best matches locally at the participating health plan sites. This will be implemented in distributed programs to examine all possible matches and 
identify matches that are considered best based on specific criteria.

We will design the process to be flexible and reusable, and we anticipate a multistep process using variables within the returned NDI data files for match selection. Processes will assess the distribution of NDI-provided matching variables such as the Status Code (indicates NDI assessment of probability of truly being alive or dead), Class Code (indicates the fact that some NDI-identifying data items used in the matching criteria are more important for determining true matches than others), assessment of item-by-item matches between health plan and NDI information, and probabilistic matching scores (score for each potential match). We will implement rules for retaining NDI matches in distributed program(s).

The NDI returns a cause-of-death code only for records that rank first in the list of possible NDI matches. If our match selection process identifies a match that was not ranked first by the NDI, this record will not have the cause-of-death information in the initial NDI+ data files. In such instances, the HPHCI will work with the NDI to attain this missing cause-of-death information. However, it is possible that the NDI will be unable to supply the cause-of-death information or may have time delays for the return of this information. If this occurs, the HPHCI may not be able to include newly supplied cause-of-death information in final use case analyses and will pilot the process for requesting and attaining this information and document lessons learned.

The HPHCI will develop a proposed standardized table structure that can be used in future studies to store information retrieved from the NDI. The HPHCI will work with the health plans to develop the ultimate table structure. The data included in this table will be maintained behind each health plan's firewall, thereby preserving the distributed nature of health plan databases. The HPHCI will document these processes and programs in a report for future use.

\section{Draft Use Case Specifications}

\section{Use Case Inclusion and Exclusion Criteria}

This study will use data captured within participating health plan databases between 2000 and 2017 (or earliest or latest available health plan data) and the most recent NDI+ data available at the time of NDI application.

Cohort 1 will include new users of select antiarrhythmic medications for men aged 45 years and older and women aged 55 years and older on the date of cohort entry between 2000 and 2017 (or earliest available health plan data). The list of select antiarrhythmic medications of interest and new-user definition is described under the Exposure Identification for the Use Case section. We chose different age cutoff values for men and women because risks of all-cause mortality and SCD vary considerably by sex. The goal is to improve the specificity of mortality and specific causes of death outcomes identified through NDI+ matching. Younger individuals are less likely to experience mortality and SCD than older individuals, and within age groups, women are less likely to experience mortality and SCD than men. The risk for SCD has been shown to increase in women after the age of 55 years [43]. All-cause mortality is also rare in younger age groups. Choosing a higher age cutoff for women is intended to decrease false-positive matches and minimize the number of NDI submissions.

We will use the entire cohort for the all-cause mortality analysis and potentially the cardiovascular death analysis. For analyses focused on SCD, we will restrict the cohorts to individuals under the age of 75 years to maintain consistency with a study by Chung et al [27], which developed and validated a computerized algorithm to identify community originating SCD. As the risk of mortality increases with age, Chung et al [27] found death certificates to be less reliable for identifying SCD in older individuals and removed patients aged $\geq 75$ years to minimize false positives. Although it may be difficult to capture nursing home stays within the participating health plan databases, to maintain consistency with the algorithm by Chung et al [27], we will exclude individuals with evidence of a nursing home stay in the baseline period. Cohort 1 entry will begin on an individual's first prescription dispensing for an oral dosage form of an antiarrhythmic medication of interest that was preceded by a 365-day baseline period with medical and pharmacy benefits (gaps in enrollment $<45$ days bridged), during which the individual has $\geq 1$ encounter with a diagnosis recorded in any care setting or an outpatient dispensing of any medication.

To mimic typical drug safety study situations in which no future information is available to determine medication users' vital status, individuals with more than one episode of new use during the study period will contribute only their first episode. This study design choice also helps avoid the selection bias that use of future information may generate. The protocol allows gaps in enrollment of $<45$ days because it is believed that these may not represent true gaps in coverage but rather administrative changes. Index date will be the date of the first eligible dispensing for a select antiarrhythmic drug of interest.

Cohort 2 will be drawn from average-risk individuals who are not current (ie, on day of cohort entry) or past (ie, before 365 days) users of antiarrhythmic medications of interest. We will match cohort 2 at a one-to-one ratio with cohort 1 based on age, sex, and health plan. Index dates will also be matched to cohort 1. We will require individuals in cohort 2 to have a 365-day baseline period with medical and pharmacy benefits (gaps in enrollment $<45$ days ignored as specified above in cohort 1) and at least one medical encounter or outpatient pharmacy dispensing claim in the previous 365 days. As in cohort 1 , cohort 2 will include the entire cohort for the all-cause mortality analysis and potentially the cardiovascular death analysis but will be restricted to individuals younger than 75 years and with no evidence of a nursing home stay in the baseline period for the SCD analyses. It is worth noting that individuals included in either cohort 1 or 2 may in fact have used antiarrhythmics medications outside of the study period or before enrolling in a participating health plan.

\section{Use Case Exposure Definitions}

We will identify select oral antiarrhythmic medications of interest using National Drug Codes. New use will be defined by excluding individuals with dispensings of class I and III antiarrhythmic drugs (all routes of administration), including amiodarone, disopyramide, dofetilide, dronedarone, flecainide, 
mexiletine, procainamide, propafenone, quinidine, and sotalol $[44,45]$, in the 365-day baseline period. Individuals with dispensings of intravenous lidocaine in the 365-day baseline period will also be excluded. Baseline exposure to adenosine A1 agonists, digoxin, phenytoin, class II $\beta$-blocker agents, and calcium channel blockers (class IV) agents will be ignored.

When creating treatment episodes, we will apply a stockpiling algorithm [46] to account for the possibility that members may refill prescriptions before the end of days' supply of their previous prescription. For example, if a member receives a 30-day dispensing for sotalol on January 1, and then receives a second 30-day dispensing on January 20, the stockpiling algorithm will adjust the second dispensing so that it starts on January 31, after the first dispensing has been used in full. The treatment episode will thus be 60 days in total, through March 1 (assuming February has 28 days). We will also implement a 14-day episode gap when creating treatment episodes to account for imperfect adherence. An episode gap is the maximum number of days of interrupted days-supply allowed between two claims for the same drugs of interest. If the number of days between when one prescription claim runs out and the next claim is smaller than or equal to the episode gap, the algorithm bridges these two claims to build a continuous treatment episode. However, if the number of days between the two claims of the same treatment exceeds the episode gap, the treatment episode ends at the end of the 14-day period. The episode gap is assessed after the claim service dates are adjusted by the stockpiling algorithm. Because we are interested in the risk of all-cause mortality and SCD for the class of medications in general and not individual antiarrhythmic medications, our analyses will focus on users of any antiarrhythmic medications of interest as a group, and the results will not be stratified by individual medication.

\section{Use Case Follow-Up and Censoring Plan}

For cohort 1, follow-up time will begin with the cohort entry-defining antiarrhythmic medication dispensing (ie, day 1 of follow-up=dispensing date) and will continue based on the treatment episode as described above. For cohort 2, follow-up time will begin on the same day as the individual's corresponding match from the antiarrhythmic medication user cohort. Follow-up will be censored upon the earliest of the following occurrences:

1. Death or specific causes of death, as determined from NDI+ data; date of death will be the last day of follow-up (both cohorts).

2. Health plan disenrollment (gaps of enrollment $<45$ days will be ignored); the last day of enrollment will be the last day of follow-up (both cohorts).

3. End of database time; database end date will be the last day of follow-up (both cohorts).

4. Initiation of an antiarrhythmic medication of interest; the day before the date of medication initiation will be the last day of follow-up (cohort 2 only).

5. Excessive allowable gap between dispensings, defined as $>14$ days between two consecutive dispensings for a study antiarrhythmic medication of interest, the last day of follow-up included will be the end of days' supply of the most recent dispensing of the study antiarrhythmic medication of interest +14 days (cohort 1 only).

The analysis will follow use case cohorts for death, SCD, and potentially cardiovascular death until censored. As linking to NDI+ data allows us to follow patients for survival through the end of the study period, if feasible, we will also conduct an analysis that ignores the censoring criteria and follows use case cohorts for death and SCD, and potentially cardiovascular death through the end of NDI+ data.

\section{Use Case Outcomes}

The primary outcomes of interest are all-cause mortality and SCD. If timeline and study resources permit, we will assess cardiovascular death as a secondary outcome of interest. Ideally, the selected outcome algorithms would: (1) facilitate the assessment of the performance or validity of the linkage to NDI+ data; (2) allow for comparing the incidences and incidence rates of all-cause mortality and specific causes of death with rates previously reported in the literature, or other national death information sources; and (3) use data retrieved from the NDI, and possibly information within health plan databases. To inform future studies, we will try to capture both medically attended and nonmedically attended deaths. We will identify these outcomes using NDI+ data and will evaluate each outcome separately. Although we will attempt to replicate SCD or cardiovascular death algorithms that have been previously validated by other studies, it may be necessary to modify or tailor the algorithms to data elements available within the health plan databases that have been converted into the Sentinel Common Data Model format [47]. Multimedia Appendix 2 $[27,48,49]$ describes the operational definitions of the outcomes. We also provide the high-level details in the following paragraphs.

We will determine all-cause mortality through linkage to the NDI+ data (all deaths, including both medically attended and nonmedically attended deaths). Two algorithms for SCD will be used, both of which exclude persons aged $\geq 75$ years. For the primary SCD definition, we will adapt an algorithm focused on community-originating events defined by Chung et al [27] for use within the health plan databases. This algorithm uses information available in claims data to exclude patients with certain conditions (Table 1 [50]) as well as cause-of-death information provided by the NDI (Table 2) [27]. The definition of secondary SCD will focus on events that occur in medical care settings. Studies examining ventricular arrhythmia diagnosis in hospital settings (ie, inpatient or emergency department) have found inpatient diagnosis codes for ventricular arrhythmia to have high positive predictive values, regardless of diagnosis code position [49,51,52]. To identify SCD outcomes originating in medical settings, we will adapt these algorithms for use within health plan databases. Secondary emergency department or inpatient diagnoses consistent with ventricular arrhythmia or sudden cardiac arrest were selected to attempt to identify events occurring in medical settings, as principal diagnosis codes would generally define conditions established after study to be chiefly responsible for admission [53]. If feasible, we may also include a sensitivity analysis exploring the principal emergency department or inpatient diagnoses consistent with ventricular 
arrhythmia or sudden cardiac arrest. Finally, we may examine cardiovascular death if it is determined to be feasible by the study team, and we would define cardiovascular death with cause-of-death codes typically used by national death data sources, such as the underlying cause of death consistent with a cardiovascular cause [25]. The algorithm parameters are outlined in more detail in Multimedia Appendix 2.

Table 1. High-risk conditions likely to be miscoded as sudden cardiac death per Ray et al $^{\mathrm{a}}$.

\begin{tabular}{|c|c|}
\hline Condition & Operational definition $^{\mathrm{b}}$ \\
\hline Cancer & $\begin{array}{l}\text { Diagnosis of cancer (except for nonmelanoma skin cancers) or select antineoplastic agents. In- } \\
\text { cludes the following neoplasms uncertain behavior ICD-9-CM }{ }^{\mathrm{c}} \operatorname{codes}^{\mathrm{d}} 235-238 \text {, except: } 238.2 \\
\text { (skin), } 238.9 \text { (site unspecified), 237.70, } 237.71 \text { (neurofibromatosis), } 238.4 \text { (polycythemia vera), } \\
238.7 \text { (lymphoproliferative disease), and } 285.22 \text { (anemia in neoplastic disease) }\end{array}$ \\
\hline HIV & $\begin{array}{l}\text { Diagnosis of HIV or use of antiretroviral agents appropriate for HIV or pentamidine (also used } \\
\text { for other major immunocompromised patients) }\end{array}$ \\
\hline Renal & $\begin{array}{l}\text { Diagnosis or procedure code for dialysis outside of the hospital (includes 996.73). Includes end- } \\
\text { stage renal disease diagnosis }(285.21,585.5,585.6) \text {, also outside of the hospital }\end{array}$ \\
\hline Liver & Diagnoses 570-573 \\
\hline Respiratory & $\begin{array}{l}\text { Diagnosis of respiratory failure, cardiorespiratory failure, or pulmonary heart disease. Also in- } \\
\text { cludes tracheostomy (excluding temporary), home oxygen, or home ventilator }\end{array}$ \\
\hline Organ transplant & $\begin{array}{l}\text { Includes kidney, heart, lung, liver, bone marrow, and pancreas. Includes complications of trans- } \\
\text { planted organ (996.8) }\end{array}$ \\
\hline Serious neuromuscular & $\begin{array}{l}\text { Multiple sclerosis (340), amyotrophic lateral sclerosis (335.20), Duchenne muscular dystrophy } \\
(335.21) \text {, Huntington chorea (333.4), quadriplegia, paraplegia, or spinal cord injury. Recent } \\
\text { stroke (inpatient with primary discharge diagnosis of 430, 431, 433.x1, 434, 436) with hemiple- } \\
\text { gia/hemiparesis }(342,438.2)\end{array}$ \\
\hline Cardiovascular congenital anomalies & 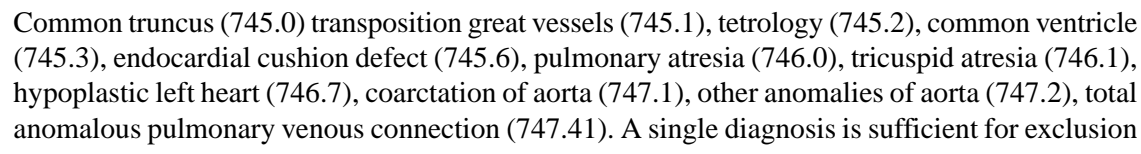 \\
\hline Other congenital anomalies/childhood conditions & $\begin{array}{l}\text { Sickle cell (282.6), cerebral palsy ( } 343) \text {, spina bifida ( } 741) \text {, Down syndrome (758.0), hydro- } \\
\text { cephalus ( } 742.3) \text {, microcephalus ( } 742.1) \text {, encephalocele (742.0), severe mental retardation ( } 318.1 \text {, } \\
\text { 318.2), cystic fibrosis }\end{array}$ \\
\hline Other end-stage illness & $\begin{array}{l}\text { (a) Hospice care; (b) diagnosis of coma, vegetative state, debility (799.3); (c) total parenteral } \\
\text { nutrition, percutaneous endoscopic gastrostomy, enteral feeding, malnutrition (260, 261, 262, } \\
263 \text { ) when these are for outpatients; (d) gangrene ( } 040 \text {, gas gangrene; } 785.4 \text { gangrene: single } \\
\text { diagnosis sufficient); (e) intravenous medications outside of the hospital, as indicated by proce- } \\
\text { dures for intravenous access outside a hospital stay period }\end{array}$ \\
\hline Drug abuse & $\begin{array}{l}\text { Includes all medications and drugs with abuse potential and with the exception of alcohol (unless } \\
\text { hospitalization with primary discharge diagnosis: } 291 . x, 303 . x, 305.0,980.0,980.9 \text {, E860.0, } \\
\text { E860.1, E860.9) and tobacco. Codes are } 292.0 \text { (drug withdrawal syndrome), 304.x (drug depen- } \\
\text { dence), 305.2-305.9 (drug abuse, except alcohol/tobacco, } 305.9 \text { is abuse not otherwise specified, } \\
\text { may be nonspecific, but better to exclude), } 965.01 \text { (accidental poisoning, heroin), } 969.6 \text { (poisoning, } \\
\text { psychodysleptic [hallucinogens]), } 970.81 \text { (cocaine poisoning, added in 2010), E8500 (heroin } \\
\text { poisoning), E8541 (psychodysleptic poisoning) }\end{array}$ \\
\hline
\end{tabular}

\footnotetext{
${ }^{\mathrm{a}}$ Ray et al [50].

${ }^{\mathrm{b}}$ Unless otherwise indicated, codes are ICD-9-CM diagnostic codes and a 3- or 4-digit code implies inclusion of all subcodes. Further, a single diagnosis is sufficient for exclusion.
}

${ }^{\mathrm{c}}$ ICD-9-CM: International Classification of Diseases, 9th Revision, Clinical Modification.

${ }^{\mathrm{d}}$ ICD-9-CM codes will be mapped to ICD-10-CM codes during the study. 
Table 2. Underlying cause-of-death diagnostic codes consistent with sudden cardiac death.

\begin{tabular}{|c|c|}
\hline International Classification of Diseases, 10th Revision Code & Description \\
\hline $\mathrm{I} 10$ & essential hypertension, not otherwise specified \\
\hline I11.9 & hypertensive heart disease, without heart failure \\
\hline $\mathrm{I} 20$ & angina pectoris \\
\hline $\mathrm{I} 21$ & acute myocardial infarction \\
\hline $\mathrm{I} 22$ & subsequent myocardial infarction \\
\hline $\mathrm{I} 23$ & $\begin{array}{l}\text { certain current complications following ST elevation and non-ST elevation myocardial } \\
\text { infarction }\end{array}$ \\
\hline $\mathrm{I} 24$ & other acute ischemic heart disease \\
\hline $\mathrm{I} 25$ & chronic ischemic heart disease \\
\hline $\mathrm{I} 25.2$ & old myocardial infarction \\
\hline $\mathrm{I} 42.8, \mathrm{I} 42.9$ & cardiomyopathy, not otherwise specified \\
\hline I46 & cardiac arrest \\
\hline I47.0 & re-entry ventricular arrhythmia \\
\hline I 47.2 & ventricular tachycardia \\
\hline I 49.0 & ventricular fibrillation and flutter \\
\hline I 49.8 & other specified cardiac arrhythmias \\
\hline I49.9 & cardiac arrhythmia, unspecified \\
\hline I51.6 & cardiovascular disease, unspecified \\
\hline I51.9 & heart disease, unspecified \\
\hline I70.9 & atherosclerosis, not otherwise specified \\
\hline R96.1 & death in $<24$ hours \\
\hline R98 & unattended death \\
\hline
\end{tabular}

\section{Use Case Analytic Plan}

For both cohort 1 and cohort 2, we will generate a baseline characteristics table. Table 3 includes the proposed list of baseline characteristics and Table 4 includes the initial code lists. We will examine demographic variables, health care utilization intensity measures, and select comorbid conditions during the 365-day baseline period. Expert opinion and review of the literature will inform variable selection. If feasible, we will also consider examining a claims-based measure of frailty [54].

Separately for all-cause mortality, SCD, and cardiovascular death, we will estimate the incidences and incidence rates as the number of outcome events during the observation period as defined in the outcome section below, divided by total persons in cohort (for incidences) or person-time (for incidence rates) of observation. All incidences or incidence rates will also be stratified by cohort. We will further estimate the incidences and incidence rates by age group $(<65,65-74, \geq 75$ [for all-cause mortality only]), sex, and cohort entry year. To facilitate comparison with previously published estimates, incidence will be presented per 1000 persons and incidence rates will be presented per 1000 person-years. For SCD, we will further estimate the incidences and incidence rates by selecting comorbidities (coronary heart disease $[35,36,55,56]$ and diabetes mellitus $[55,57,58])$. If feasible, to facilitate comparisons with the literature, we will include analyses using multiple age subgroups (eg, age subgroup 1: 45-54, 55-64, 65-74, 75-84, and $\geq 85$ years; age subgroup 2: 45-46, 47-51, 52-56, 57-61, 62-66, 67-71, 72-74; and 45-54, 55-64, 65-74) [35,64].

Although medical records, autopsy reports, ambulance, or other similar records might be used to validate death information attained from the NDI, this type of evaluation is beyond the scope of this study. If project timelines permit, we will consider two other indirect approaches to evaluate the performance of the NDI+ data linkage. The first strategy would involve comparing rates of mortality and SCD with rates previously reported in the literature. We will describe and examine the incidences and incidence rates of mortality and SCD in the use case cohorts and compare them with estimates previously reported in the literature. This comparison will provide indirect evidence for outcome definition accuracy. For all-cause mortality, we will compare our estimated incidence rates with those from the CDC Wonder data [65]. For SCD, we will compare the incidence rates estimated in cohort 1 with the range of incidence rates reported in the literature (Table 5). In general, we will examine and compare the incidences and incidence rates in cohort 2 with national data sources such as CDC Wonder and studies included in the literature because such data sources and studies focus on the overall population and are thus are comparable with our cohort 2. 
Table 3. Baseline characteristics associated with users of antiarrhythmic medications (cohort 1) and among the average-risk population (cohort 2) identified at participating health plans, 2000 to 2017 or latest health plan and National Death Index Plus data availability.

\begin{tabular}{llll}
\hline Demographics & Cohort $1^{\text {a }}$ & Cohort $2^{\text {a }}$
\end{tabular}

Age groups $(<65,65-74, \geq 75)$

Mean age, in years $( \pm \mathrm{SD})$

$\begin{array}{ll}\text { N/A } & \text { N/A } \\ \text { N/A } & \text { N/A } \\ \text { N/A } & \text { N/A }\end{array}$

Sex, \% female

N/A

Health care utilization intensity measures during the baseline period

\#hospitalizations

N/A

N/A

\#emergency department visits

N/A

N/A

\#ambulatory care visits

N/A

N/A

\#unique medications dispensed

N/A

N/A

Comorbid conditions, identified during the baseline period

Arrhythmia/conduction disorder, by type

N/A

N/A

Atrial fibrillation and flutter

N/A

N/A

Paroxysmal ventricular tachycardia

N/A

N/A

Ventricular fibrillation and flutter

N/A

N/A

Paroxysmal supraventricular tachycardia

N/A

N/A

Unspecified paroxysmal tachycardia

N/A

N/A

Premature beats

N/A

N/A

Other specified or unspecified cardiac dysrhythmia

N/A

N/A

Cerebrovascular disease

N/A

N/A

Coronary heart disease

N/A

N/A

Diabetes mellitus

N/A

N/A

Heart failure/cardiomyopathy

N/A

N/A

Cardioverter-defibrillator/pacemaker

N/A

N/A

Hyperlipidemia

N/A

N/A

Hypertension

N/A

N/A

Kidney disease

N/A

N/A

Circulatory system disease

N/A

N/A

Seizure disorder

N/A

N/A

Smoking ${ }^{\mathrm{b}}$

N/A

N/A

Obesity $^{\mathrm{b}}$

N/A

N/A

\section{Charlson comorbidity score}

0

1

$\geq 2$

Risk of Torsades de pointes (TdP), per CredibleMeds [28]

\author{
Known risk \\ Possible risk \\ Conditional risk \\ To be avoided by congenital long QT patients
}

N/A

N/A

N/A

N/A

N/A

N/A

N/A

N/A

N/A

N/A

N/A

N/A

${ }^{\mathrm{a}}$ This table represents planned study analyses, and cells are blank because analyses are not yet complete. 
${ }^{b}$ Although these covariates are often not well-captured in claims data, given the importance of these factors we will include them with the understanding under capture of these elements is expected within source data.

${ }^{\mathrm{c}}$ N/A: Not yet available 
Table 4. International Classification of Diseases, 9th Revision, Clinical Modification, diagnosis, and procedure codes for identifying comorbidities and other conditions. ${ }^{\mathrm{a}}$

\begin{tabular}{|c|c|}
\hline Baseline table conditions & Codes \\
\hline Atrial fibrillation and flutter & ICD-9 ${ }^{\text {b}}-\mathrm{CM}: 427.31$ and 427.32 \\
\hline Paroxysmal ventricular tachycardia & ICD-9-CM: 427.1 \\
\hline Ventricular fibrillation and flutter & ICD-9-CM: 427.4X \\
\hline Paroxysmal supraventricular tachycardia & ICD-9-CM: 427.0 \\
\hline Unspecified paroxysmal tachycardia & ICD-9-CM: 427.2 \\
\hline Premature beats & ICD-9-CM: 427.6X \\
\hline Other specified or unspecified cardiac dysrhythmia & ICD-9-CM: $427.8 \mathrm{X}$ or $427.9 \mathrm{X}$ \\
\hline \multirow[t]{6}{*}{ Cerebrovascular disease } & ICD-9-CM: 430.X-432.X \\
\hline & $433.01,433.11,433.21,433.31,433.81,433.91,434 . x, 436$ \\
\hline & $\begin{array}{l}362.34,433.00,433.10,433.20,433.30,433.80,433.90,435 . x, 437.0,437.1 \\
437.9,438 . x\end{array}$ \\
\hline & $38.11,38.12,38.41,38.42$ \\
\hline & $325 . X, 437.6$ \\
\hline & $781.4,784.3,997.0$ \\
\hline Coronary heart disease $[35,36,55,56]$ & ICD-9-CM: 410.XX, 412.XX, 412, 413.X, 414.XX \\
\hline Diabetes mellitus $[55,57,58]$ & ICD-9-CM: 250.XX \\
\hline Heart failure/cardiomyopathy $[35,59,60]$ & ICD-9-CM: 402.X1, 404.X1, 404.X3, 428.XX \\
\hline \multirow[t]{4}{*}{ Cardioverter-defibrillator/pacemaker } & $\begin{array}{l}\text { ICD-9-CM: 996.01, 996.04, V45.X, V53.31, V53.32; ICD-9-CM Volume } 3 \\
\text { procedure codes: } 00.50-00.54,37.7 X, 37.8 X, 37.94,37.95,37.96,37.97, \\
37.98,89.45-89.49\end{array}$ \\
\hline & $\begin{array}{l}\text { CPT-4 } 4^{\mathrm{C}} \text { Category II codes: } 00530,33200-33249,33262-33264,93280 \text {, } \\
\text { 93288, 93294, 93296, 93297, 93640, 93641, 93642 }\end{array}$ \\
\hline & CPT-4 Category III codes: $0319 \mathrm{~T}-0328 \mathrm{~T}$ \\
\hline & $\begin{array}{l}\text { Healthcare Common Procedure Coding System codes (HCPCS): C1721, } \\
\text { C1722, C1777, C1779, C1785, C1786, C1882, C1895, C1896, C1898, C1899, } \\
\text { C2619, C2620, C2621, E0610, E0615, E0617, G0297, G0298, G0299, G0300, } \\
\text { G0448, K0606, K0607, K0608, K0609 }\end{array}$ \\
\hline Hyperlipidemia & ICD-9-CM: 272.0X, 272.1X, 272.2X, 272.3X, 272.4X, 272.7X \\
\hline Hypertension & ICD-9-CM: 401-405 (excluding 402.01, 402.11, 402.91) \\
\hline Chronic kidney disease $[58,61,62]$ & ICD-9-CM: 585.3, 585.4, 585.5 \\
\hline $\begin{array}{l}\text { Circulatory system disease, thereby capturing rheumatic fever, } \\
\text { rheumatic heart disease, hypertensive disease, ischemic heart disease, } \\
\text { diseases of pulmonary circulation, other heart disease, cerebrovascular } \\
\text { disease, arterial disease, and venous disease }\end{array}$ & ICD-9-CM: 390.X-459.X \\
\hline Seizure disorder & ICD-9-CM: 345x, 780.3x (not 780.31) \\
\hline Smoking tobacco $[55]^{\mathrm{e}}$ & $\begin{array}{l}\text { Presence of any the following codes on any claim type: ICD-9-CM: 305.1, } \\
\text { 649.0X, 989.84, V15.82; CPT-I: 83887, 99406, 99407; CPT-II: 1034F, 1035F, } \\
\text { 4000F, 4001F, 4004F; HCPCS: C9801, C9802, G0375, G0376, G0436, } \\
\text { G0437, G8093, G8094, G8402, G8403, G8453, G8454, G8455, G8456, } \\
\text { G8688, G9016, S4990, S4991, S4995, S9075, S9453; NDC': nicotine replace- } \\
\text { ment, varenicline, Zyban (brand only) }\end{array}$ \\
\hline Obesity $[55,63]^{\mathrm{e}}$ & $278.0 \mathrm{X}$ \\
\hline \multicolumn{2}{|l|}{ Conditions included in the $\operatorname{SCD}^{\mathrm{f}}$ subgroup analyses } \\
\hline Coronary heart disease $[35,36,55,56]$ & 410.XX, 412.XX, 412, 413.X, 414.XX \\
\hline Diabetes mellitus $[55,57,58]$ & 250.XX \\
\hline
\end{tabular}

${ }^{a}$ Codes will be mapped to ICD-10-CM (ICD-10: International Classification of Diseases, 10th Revision) codes during the study

${ }^{\mathrm{b}}$ ICD-9-CM: International Classification of Diseases, 9th Revision. 
${ }^{\mathrm{c}}$ CPT-4: Current Procedural Terminology-4.

${ }^{\mathrm{d}}$ NDC: National Drug Code.

${ }^{\mathrm{e}}$ Although obesity and smoking are often not well-captured in claims data, we will include them with the understanding under capture of these elements is expected within source data.

${ }^{\mathrm{f}} \mathrm{SDC}$ : sudden cardiac death. 
Table 5. Published incidences or incidence rates of sudden cardiac death and all-cause mortality among users of antiarrhythmic medications and among the average-risk population.

\begin{tabular}{|c|c|c|c|c|}
\hline \multirow[t]{2}{*}{ Patient characteristics } & \multicolumn{2}{|c|}{$\begin{array}{l}\text { Events per person or person-years, and/or risk of sudden cardiac } \\
\text { death by patient characteristics }\end{array}$} & \multicolumn{2}{|c|}{$\begin{array}{l}\text { Events per person or person-years or risk of all-cause } \\
\text { mortality by patient characteristics }{ }^{\mathrm{a}}\end{array}$} \\
\hline & $\begin{array}{l}\text { Antiarrhythmic } \\
\text { medication users }\end{array}$ & $\begin{array}{l}\text { Average-risk population, without respect to } \\
\text { antiarrhythmic use }\end{array}$ & $\begin{array}{l}\text { Antiarrhythmic medica- } \\
\text { tion users }\end{array}$ & $\begin{array}{l}\text { Average-risk population, } \\
\text { without respect to antiar- } \\
\text { rhythmic use }\end{array}$ \\
\hline Overall & N/A & $\begin{array}{l}0.5-1.5 / 1000 \text { persons, Deo et al [66], Chugh } \\
\text { et al [36], Straus et al [67] }\end{array}$ & $\mathrm{N} / \mathrm{A}^{\mathrm{c}}$ & N/A \\
\hline Female & N/A & $\begin{array}{l}\text { Female<male, Zheng et al [43], Kannel et } \\
\text { al [68], Stecker et al [37]; Beginning at age } \\
\text { 35, incidence increases monotonically until } \\
\text { age } 85 \text { (Zheng et al [43], Chugh et al [36], } \\
\text { Straus et al [67]) }\end{array}$ & N/A & N/A \\
\hline $55-64$ years & N/A & $1.0 / 1000$ persons & N/A & N/A \\
\hline $65-74$ years & N/A & $2.8 / 1000$ persons & N/A & N/A \\
\hline Male & N/A & $\begin{array}{l}\text { Male>female, Zheng et al [43], Kannel et } \\
\text { al [59], Stecker et al [37]; Beginning at age } \\
\text { 35, incidence increases monotonically until } \\
\text { age } 85 \text { (Zheng et al [43], Chugh et al [36], } \\
\text { Straus et al [67]) }\end{array}$ & N/A & N/A \\
\hline $45-54$ years & N/A & $1.2 / 1000$ persons & N/A & N/A \\
\hline $55-64$ years & N/A & $2.8 / 1000$ persons & N/A & N/A \\
\hline $65-74$ years & N/A & $6.0 / 1000$ persons & N/A & N/A \\
\hline Year & N/A & $\begin{array}{l}\text { Given that sudden cardiac death incidence } \\
\text { declined from 1979-1998 [69], it may be } \\
\text { reasonable to expect a small decline in inci- } \\
\text { dence from 2001-2002 to } 2009-2010 \text {. This } \\
\text { is likely driven by a reduction in coronary } \\
\text { heart disease. Yet, any small decline could } \\
\text { be halted by the increasing incidence of } \\
\text { heart failure [70] }\end{array}$ & N/A & N/A \\
\hline $1990-1995$ & N/A & $1.0 / 1000$ person-years (for 1990s) [71] & N/A & N/A \\
\hline 1996-1999 & N/A & 0.91-1.0/1000 persons [67] & N/A & N/A \\
\hline 2000-2004 & N/A & 0.79/1000 persons [67] & N/A & N/A \\
\hline $2005-2009$ & N/A & N/A & N/A & N/A \\
\hline $2010-2014$ & N/A & N/A & N/A & N/A \\
\hline $2015-2017$ & N/A & N/A & N/A & N/A \\
\hline Comorbidities & & & N/A & \\
\hline Coronary heart disease & & $\begin{array}{l}\text { 2-12X increased risk, Chugh et al [36], } \\
\text { Kannel et al }[56,59] \text {, Albert et al [72] }\end{array}$ & N/A & N/A \\
\hline Presence & N/A & 4.6-25.1/1000 persons & N/A & N/A \\
\hline Absence & N/A & $1.5-3.6 / 1000$ persons & N/A & N/A \\
\hline Diabetes mellitus & & $\begin{array}{l}\text { 2-3 times increased risk, Jouven et al } \\
\text { [73,74], Albert et al [72], Vasiliadis et al } \\
\text { [58]; 1.3/1000 person-years in sulfonylurea } \\
\text { users Leonard et al [75] }\end{array}$ & N/A & N/A \\
\hline Presence & N/A & N/A & N/A & N/A \\
\hline Absence & N/A & N/A & N/A & N/A \\
\hline
\end{tabular}

${ }^{\mathrm{a}}$ Estimates from CDC Wonder or other national death data sources.

${ }^{\mathrm{b}}$ Estimates located at the time or protocol development were included, blank cells indicate no available information at the time of protocol development. ${ }^{\mathrm{c}}$ N/A: Not yet available. 
The second strategy would be to examine the concordance between NDI data and health plan death data. Several participating health plans collect death information through linkage with the state death records. If timeline and resources permit, this project will attempt to identify time periods in which death information is considered well populated within each health plan and examine the concordance of this information with information attained through linkage to NDI data. At health plans that do not attain death information from state death records, if timeline and resources permit, we will consider examining discharge disposition (ie, discharged expired) for in-hospital deaths included in health plan databases, and comparing this information with NDI data. Although we expect agreement between both data sources, such comparisons will assist in any evaluations of matching with NDI data and would also provide indirect evidence for accuracy (Table 6).

Table 6. Example concordance matrix, all-cause mortality (to be repeated for each health plan and time period of interest ${ }^{\mathrm{a}}$ ).

\begin{tabular}{lll}
\hline NDI $^{\mathrm{b}}$ data & Health plan data & \\
& ${\text { Health plan 1 death }=\mathrm{yes}^{\mathrm{c}}}^{\text {Health plan 1 death=no }}$ \\
\hline NDI death=yes & A & $\mathrm{C}$ \\
NDI death=no & B & $\mathrm{D}$ \\
\hline
\end{tabular}

${ }^{a}$ Death data within the health plan databases are known to be incomplete. Time period of interest will be time periods in which participating health plans are confident in the completeness of their death data. Additional stratifications, such as stratifying results by data source (eg, hospital discharge disposition) may be conducted.

${ }^{b}$ NDI: National Death Index.

cNo gold standard, can only describe concordance and discordance (ie, "a" and "d" concordance, "b" and "c" discordant).

\section{Proposed Use Case Workflow}

Below, we summarize a high-level overview of steps to execute the use case.

1. Study team will finalize the following:

- Use case specifications

- Criteria for NDI patient record submission

- The limited set of identifiable data elements needed for NDI+ matching

- Analytic plan

2. The HPHCI will develop a cohort identification program that will query health plan databases formatted in the Sentinel Common Data Model. This program will identify individuals who meet the criteria entry into the cohorts as well as for matching with the NDI at the participating health plans; the program will be distributed to participating health plans for local execution.

3. Participating health plans will populate files to be sent directly to the NDI from their operational data source with the NDI required patient identifiers (eg, name, date of birth, age, social security number).

4. The HPHCI will develop a data quality assurance and check program that will ensure that the data files to be sent to the NDI are completely populated, meet NDI's minimal criteria as eligible for matching, and are correctly formatted. The program will be distributed to participating health plans for local execution.

5. Participating health plans will individually submit the necessary quality-checked data files to the NDI.

6. The NDI will conduct matching activities and return files to health plans.

7. The HPHCI will develop a program to remove all identifiable data, identify matches to be saved, and create analytic files with minimally necessary information from health plan data and the NDI. The program will be distributed to participating health plans for local execution.
8. The HPHCI will develop an analytic program to generate information necessary to conduct the statistical analysis for the use case. The program will be distributed to participating health plans for local execution, and only summary-level information will be shared between health plans and the coordinating center.

9. The HPHCI will retrieve output produced by health plans and complete the statistical analysis.

10. The HPHCI will lead the writing of the final project report and standard operating procedures.

\section{Results}

We will use the linked health plan and NDI+ data sets to estimate the incidence and incidence rate of mortality and specific causes of death within the use case and compare the results with previously reported estimates. These comparisons provide an opportunity to assess the performance of the developed NDI+ linkage approach and lessons to future studies requiring NDI+ linkage in distributed database settings. This study is approved by the Harvard Pilgrim Health Care IRB in Boston, MA. We will present results and the reusable NDI+ linkage approach to the FDA, at academic conferences, and publish in peer-reviewed journals. We have attained NDI approval and are summarizing the administrative processes that we developed and implemented for use in other studies. Currently, the study team is in the process of developing and testing the distributed NDI+ linkage process as described above and anticipates having initial results in early 2021.

\section{Discussion}

\section{Use Case Limitations}

Given that the outcomes of death, SCD, and cardiovascular death could be rare in the general population; large cohorts will be required to adequately address the use case. Although we anticipate potentially large available sample sizes within the 
use case, estimates of incidences and incidence rates in small subgroups may be imprecise. If it is not feasible to perform linkage for all the identified individuals, we will develop a sampling scheme that will still allow us to pilot the linkage methods.

The incidences and incidence rates estimated from our study may not be directly comparable with those reported in the literature. For example, our proposed use case exclusion conditions and matching of persons in cohort 2 with persons of cohort 1 by age, sex, health plan, and index dates (thereby making the population in cohort 2 more similar to the antiarrhythmic medication users in cohort 1), may make our population of interest different from other populations studied previously. In addition, privately insured patients may have lower mortality rates compared with the general population owing to better health care access. Due to these anticipated differences, the comparison between the incidences and incidence rates derived from our study and the literature-reported estimates will be performed qualitatively.

Some of the outcome algorithms used in this study have been validated in other data sources but have not been validated specifically within the participating health plan databases. For example, the SCD algorithm by Chung et al [27] was originally developed and implemented within a population including Tennessee Medicaid recipients aged 30-74 years. While the participating health plans in this study include mainly commercially insured populations, Medicaid beneficiaries included in the study by Chung et al may be different (eg, more vulnerable, economically disadvantaged). However, in our study, one participating health plan also provides Tennessee Medicaid data, and thus analyses stratified by health plan may inform potential population differences. In addition, the Chung et al study relied on both death certificate data and state hospital discharge data when developing a computerized algorithm to identify SCD. Although not all information included in the Chung et al study is available to participating health plans, the selected algorithms can be adapted to utilize data elements available within health plan data. The potential inability to replicate validated computerized algorithms developed in other data sources in their entirety is a study limitation.

Health plan disenrollment will be used as a proxy to select individuals for linkage to NDI+ data. Most individuals who disenroll from their health plans have not died but instead have lost or changed their insurance coverage. If individuals in an average-risk cohort are healthier and more likely to change health insurance plans, they may have higher rates of disenrollment than antiarrhythmic medication users. These higher rates of disenrollment are unlikely to reflect death and may lead to a disproportionate number of submissions to the NDI that do not result in a death record. We expect that the incidence of death and SCD will be low and disenrollment rates will be high (approximately $20 \%-30 \%$ per year). Therefore, we expect that our NDI+ data linkage activity will yield false positives. However, given the goal of this project is to determine an algorithm for identifying individuals to submit to NDI in future studies, lessons learned concerning false positives during analyses examining concordance between health plan death data and NDI data as well as ways to refine the disenrollment algorithm will inform future NDI+ data linkage studies.

In general, study results will be highly dependent on the quality of the NDI+ data linkage. Some identifiers that would be highly desirable to use as keys for linkage may not be uniformly available across all health plans. For example, provision of social security number information to the NDI will likely increase the number of correct matches. However, social security number information is not always complete in health plans. A lack of social security number submittal could result in a greater number of multiple matches returned by the NDI, which requires resolution and selection. The study team is designing strategies to optimize the selection of the best match. However, regardless of whether a social security number is submitted, it is possible that an incorrect match could be selected. In addition, if personal identifiers submitted by the health plans are incorrect, mismatches between health plan and NDI+ data could also occur. Such mismatches will most likely result in misclassifying patients who are dead as alive (ie, unable to locate a death in NDI+ data). The study team has anticipated these potential issues and is designing quality assurance steps where possible. To inform future studies, we will summarize lessons learned about ways to maximize the quality of the NDI+ data linkage.

\section{Study Strengths}

The NDI is currently the best data source of death and cause-of-death information for large-scale population-based epidemiologic studies in the United States. We anticipate the development of standardized processes to attain and analyze death and cause-of-death information from the NDI will provide avenues for multisite research networks to efficiently obtain more complete death information. As many health plans that participate in multisite research networks do not have complete capture of out-of-hospital deaths or cause-of-death information, the ability to efficiently attain this information from the NDI may provide opportunities to answer a wider variety of mortality-related research questions. We also anticipate that our newly developed NDI+ linkage methods will enhance the FDA's ability to answer mortality-related safety questions in distributed networks.

Although conducted independently of the Sentinel Initiative, our study will leverage the infrastructure of a well-known distributed network, the FDA Sentinel System [7,8], to develop and test reusable administrative and technical processes for linking multiple health plan databases with NDI+ data. Leveraging the Sentinel System infrastructure will ensure that health plan databases are standardized and research ready. As our study sites are health plans that participate in the Sentinel System, administrative processes or NDI+ data linkage programs we will develop could be reused by the Sentinel System as well as other multisite studies using distributed research networks. As the Sentinel System publishes its common data model publicly $[7,8]$ and in some instances provides translation code to help certain data sources with data conversion, other researchers would have the ability to directly transform other health plan databases into the Sentinel Common Data Model and directly use any developed NDI+ data linkage programs from this study for NDI+ data linkage. In addition, we will test 
our newly developed NDI+ data linkage methods among a diverse group of participating health plans (ie, national insurers, regional health plans, and integrated delivery systems, which cover both commercial and public insurance programs). We anticipate that our testing will ensure that developed NDI+ data linkage processes will be applicable to multiple settings.

Another strength of this study is our focus on developing a distributed process for NDI+ data linkage in multisite research studies. A distributed approach allows individual study sites to maintain physical and operational control over their electronic health data behind their respective firewalls, thus promoting data sharing by protecting patient privacy, data security, and proprietary interests [9-11]. We will develop methods that will allow health plans to work directly with the NDI and eliminate sharing of identifiable patient information between participating health plans or the coordinating center.

Finally, we chose our antiarrhythmic medications use case to robustly test the NDI+ data linkage processes within a cohort at high risk of death (antiarrhythmic medication users) and a cohort at average risk of death (nonusers matched by age and sex to antiarrhythmic medication users). This use case should provide sufficient sample sizes for patients who are dead and alive. To indirectly validate our newly developed linkage methods, we plan to examine the concordance between NDI data and health plan death data as well as compare rates of mortality and SCD with rates previously reported in the literature. Information we will gather as part of these indirect validation activities will provide some metrics for the performance of our NDI+ data linkage methods.

\section{Anticipated Study Contributions}

We anticipate this project to provide future studies with a tested administrative workflow that facilitates efficient, coordinated, multicenter IRB review and approval for linking health plan data with NDI+ data in accordance with the revised Common Rule. We will also provide recommendations for completing a successful NDI application, along with lessons learned that may help future studies navigate the process more efficiently. We will develop a standardized and reusable distributed technical process for efficiently attaining and analyzing death and cause-of-death information from the NDI across multiple health plan databases without sharing protected health information between health plans or with the coordinating center. Our study will also provide considerations for determining which patients to submit to the NDI for matching. We will leverage lessons learned by developing and testing our NDI+ data linkage methods with the goal of improving the ability to answer mortality-related research questions within multisite studies based in distributed data networks.

\section{Acknowledgments}

This project is supported by the US Department of Health and Human Services (HHS), Assistant Secretary of Planning and Evaluation, Patient Centered Outcomes Research Trust Fund, through the Food and Drug Administration contract number HHSF223301710132C, project titled, "A Reusable Method to Link Health Plan Data with the National Death Index Plus to Examine the Associations Between Medical Products and Death and Causes of Death." This paper reflects the views of the authors and does not necessarily represent the FDA's views or policies.

A previous mini-Sentinel project workgroup laid an important groundwork for this project and included the following members and organizations: Steven Bird, Victor Crentsil, David Graham, Terry Harrison, Monika Houstoun, Stephanie Keeton, Susan Lu, Katrina Mott, Rita Ouellet-Hellstrom, Simone Pinheiro, Marsha Reichman, Marry Ross Southworth, and Anne Tobenkin of Office of Surveillance and Epidemiology, Center for Drug Evaluation and Research, US Food and Drug Administration; Eric Frimpong and Margie Goulding of Harvard Pilgrim Health Care Institute; Sascha Dublin, Monica Fujii, Kristina Hansen, Jennifer Nelson, and Robert Wellman of Group Health Research Institute; Susan Andrade of Meyers Primary Care Institute; Nancy Lin of OptumInsight Life Sciences Inc; Todd Lee of University of Illinois at Chicago; Rajat Deo and Sean Hennessy of Center for Pharmacoepidemiology Research and Training, Department of Biostatistics, Epidemiology, and Informatics, Perelman School of Medicine, University of Pennsylvania; and James Floyd, Bruce Psaty and David Siscovik of University of Washington Department of Biostatistics.

Furthermore, the authors acknowledge the helpful input and contributions to the current project as follows: Noelle Cocoros, Qoua Her, April DuCott, Matthew Lakoma, Christine Draper, Zilu Zhang, Elizabeth Dee, and Susan Forrow of Harvard Pilgrim Health Care Institute; Jacqueline M Major, Deloris Willis, Carla Walls, Denise Jones, and Rita Noel of Office of Surveillance and Epidemiology, Center for Drug Evaluation and Research, US Food and Drug Administration; Sonal Singh of Meyers Primary Care Institute; and Samantha Soprano of Center for Pharmacoepidemiology Research and Training, Department of Biostatistics, Epidemiology, and Informatics, Perelman School of Medicine, University of Pennsylvania.

\section{Authors' Contributions}

CF collaborated with coauthors on the study design and wrote the protocol. All authors reviewed and approved the final manuscript.

\section{Conflicts of Interest}

CEL serves on the Executive Committee of the University of Pennsylvania's Center for Pharmacoepidemiology Research and Training. The Center receives funds for education from Pfizer and Sanofi. He recently received honoraria from the American College of Clinical Pharmacy Research Institute and the University of Florida College of Pharmacy. CEL's research is funded 
by the American Diabetes Association, Food and Drug Administration, and National Institutes of Health. CEL is a Special Government Employee of the Food and Drug Administration.

\section{Multimedia Appendix 1}

Proposed National Death Index submission criteria to be used to determine which individuals will be initially selected for sending to the NDI, thereby obtaining death and cause-of-death information.

[PPTX File, 47 KB-Multimedia Appendix 1]

\section{Multimedia Appendix 2}

Operational definitions of outcomes of interest in the use case.

[PPTX File, 53 KB-Multimedia Appendix 2]

\section{References}

1. Questions and Answers on FDA's Adverse Event Reporting System (FAERS). US Food and Drug Administration. 2018. URL: https://www.fda.gov/drugs/surveillance/questions-and-answers-fdas-adverse-event-reporting-system-faers [accessed 2018-03-28]

2. Colman E, Szarfman A, Wyeth J, Mosholder A, Jillapalli D, Levine J, et al. An evaluation of a data mining signal for amyotrophic lateral sclerosis and statins detected in FDA's spontaneous adverse event reporting system. Pharmacoepidemiol Drug Saf 2008 Nov;17(11):1068-1076. [doi: 10.1002/pds.1643] [Medline: 18821724]

3. Wysowski DK, Swartz L. Adverse drug event surveillance and drug withdrawals in the United States, 1969-2002: The importance of reporting suspected reactions. Arch Intern Med 2005 Jun 27;165(12):1363-1369. [doi:

10.1001/archinte.165.12.1363] [Medline: 15983284]

4. Wong CK, Ho SS, Saini B, Hibbs DE, Fois RA. Standardisation of the FAERS database: a systematic approach to manually recoding drug name variants. Pharmacoepidemiol Drug Saf 2015 Jul;24(7):731-737. [doi: 10.1002/pds.3805] [Medline: 26017154]

5. Moore TJ, Cohen MR, Furberg CD. Serious adverse drug events reported to the food and drug administration, $1998-2005$. Arch Intern Med 2007 Sep 10;167(16):1752-1759. [doi: 10.1001/archinte.167.16.1752] [Medline: 17846394]

6. Weiss-Smith S, Deshpande G, Chung S, Gogolak V. The FDA drug safety surveillance program: adverse event reporting trends. Arch Intern Med 2011 Mar 28;171(6):591-593. [doi: 10.1001/archinternmed.2011.89] [Medline: 21444854]

7. Platt R, Brown JS, Robb M, McClellan M, Ball R, Nguyen M, et al. The FDA sentinel initiative- an evolving national resource. N Eng J Med 2018;379(9):2091-2093. [doi: 10.1056/NEJMp1809643] [Medline: 30485777]

8. Behrman RE, Benner JS, Brown JS, McClellan M, Woodcock J, Platt R. Developing the sentinel system--a national resource for evidence development. N Engl J Med 2011 Feb 10;364(6):498-499. [doi: 10.1056/NEJMp1014427] [Medline: 21226658]

9. Toh S, Platt R, Steiner JF, Brown JS. Comparative-effectiveness research in distributed health data networks. Clin Pharmacol Ther 2011;90(6):883-887. [doi: 10.1038/clpt.2011.236] [Medline: 22030567]

10. Maro JC, Platt R, Holmes JH, Strom BL, Hennessy S, Lazarus R, et al. Design of a national distributed health data network. Ann Intern Med 2009 Sep 1;151(5):341-344. [doi: 10.7326/0003-4819-151-5-200909010-00139] [Medline: 19638403]

11. Brown JS, Holmes JH, Shah K, Hall K, Lazarus R, Platt R. Distributed health data networks: a practical and preferred approach to multi-institutional evaluations of comparative effectiveness, safety, and quality of care. Med Care 2010 Jun;48(6 Suppl):S45-S51. [doi: 10.1097/MLR.0b013e3181d9919f] [Medline: 20473204]

12. Her Q, Malenfant J, Zhang Z, Vilk Y, Young J, Tabano D, et al. Distributed regression analysis application in large distributed data networks: analysis of precision and operational performance. JMIR Med Inform 2020 Jun 4;8(6):e15073 [FREE Full text] [doi: 10.2196/15073] [Medline: $\underline{\text { 32496200] }}$

13. Fact sheet: national death index. National Center for Health Statistics. 2018. URL: $\underline{\text { https://www.cdc.gov/nchs/about/factsheets/ }}$ factsheet_ndi.htm [accessed 2018-03-28]

14. da Graca B, Filardo G, Nicewander D. Consequences for healthcare quality and research of the exclusion of records from the death master file. Circ Cardiovasc Qual Outcomes 2013;6(1):124-128. [doi: 10.1161/CIRCOUTCOMES.112.968826] [Medline: 23322808]

15. Brooks EG, Reed KD. Principles and pitfalls: a guide to death certification. Clin Med Res 2015 Jun;13(2):74-82; quiz 83-4. [doi: $10.3121 / \mathrm{cmr} .2015 .1276]$ [Medline: 26185270]

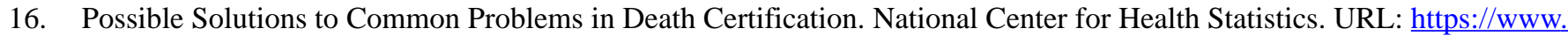
cdc.gov/nchs/nvss/ [accessed 2017-06-24]

17. Hanzlick R. The conversion of coroner systems to medical examiner systems in the United States: a lull in the action. Am J Forensic Med Pathol 2007 Dec;28(4):279-283. [doi: 10.1097/PAF.0b013e31815b4d5a] [Medline: 18043011]

18. Ives DG, Samuel P, Psaty BM, Kuller LH. Agreement between nosologist and cardiovascular health study review of deaths: implications of coding differences. J Am Geriatr Soc 2009 Jan;57(1):133-139 [FREE Full text] [doi:

10.1111/j.1532-5415.2008.02056.x] [Medline: 19016930] 
19. Lakkireddy DR, Basarakodu KR, Vacek JL, Kondur AK, Ramachandruni SK, Esterbrooks DJ, et al. Improving death certificate completion: a trial of two training interventions. J Gen Intern Med 2007 Apr;22(4):544-548 [FREE Full text] [doi: 10.1007/s11606-006-0071-6] [Medline: 17372807]

20. Kircher T, Anderson RE. Cause of death. Proper completion of the death certificate. J Am Med Assoc 1987 Jul 17;258(3):349-352. [Medline: 3599328]

21. Folsom AR, Gomez-Marin O, Gillum RF, Kottke TE, Lohman W, Jacobs DJ. Out-of-hospital coronary death in an urban population--validation of death certificate diagnosis. The Minnesota heart survey. Am J Epidemiol 1987 Jun;125(6):1012-1018. [doi: 10.1093/oxfordjournals.aje.a114617] [Medline: 3578243]

22. Lenfant C, Friedman L, Thom T. Fifty years of death certificates: the Framingham heart study. Ann Intern Med 1998 Dec 15;129(12):1066-1067. [doi: 10.7326/0003-4819-129-12-199812150-00013] [Medline: 9867763]

23. Olubowale OT, Safford MM, Brown TM, Durant RW, Howard VJ, Gamboa C, et al. Comparison of expert adjudicated coronary heart disease and cardiovascular disease mortality with the national death index: results from the reasons for geographic and racial differences in stroke (REGARDS) study. J Am Heart Assoc 2017 May 3;6(5). [doi: 10.1161/JAHA.116.004966] [Medline: 28468785]

24. Sathiakumar N, Delzell E, Abdalla O. Using the national death index to obtain underlying cause of death codes. J Occup Environ Med 1998 Sep;40(9):808-813. [doi: 10.1097/00043764-199809000-00010] [Medline: 9777565]

25. Miniño A, Klein R. Mortality From Major Cardiovascular Diseases: United States, 2007. National Center for Health Statistics. 2010. URL: https://www.cdc.gov/nchs/data/hestat/cardio2007/cardio2007.htm [accessed 2020-07-31]

26. Kodadhala V, Obi J, Wessly P, Mehari A, Gillum RF. Asthma-related mortality in the United States, 1999 to 2015 : a multiple causes of death analysis. Ann Allergy Asthma Immunol 2018 Jun;120(6):614-619. [doi: 10.1016/j.anai.2018.03.005] [Medline: 29548908]

27. Chung CP, Murray KT, Stein CM, Hall K, Ray WA. A computer case definition for sudden cardiac death. Pharmacoepidemiol Drug Saf 2010 Jun;19(6):563-572 [FREE Full text] [doi: 10.1002/pds.1888] [Medline: 20029823]

28. Combined list of all QT drugs and the list of drugs to avoid for patients with congenital long QT syndrome. CredibleMeds. 2017. URL: https://www.crediblemeds.org/index.php [accessed 2017-06-22]

29. Torres V, Flowers D, Somberg JC. The arrhythmogenicity of antiarrhythmic agents. Am Heart J 1985 May;109(5 Pt 1):1090-1097. [doi: 10.1016/0002-8703(85)90253-4] [Medline: 3993517]

30. Cowan JC, Bourke J, Campbell RWF. Arrhythmogenic effects of antiarrhythmic drugs. Eur Heart J 1987 Mar;8(Suppl A):133-136. [doi: 10.1093/eurheartj/8.suppl a.133] [Medline: 3582392]

31. Oliver MF. Metabolic causes and prevention of ventricular fibrillation during acute coronary syndromes. Am J Med 2002 Mar;112(4):305-311. [doi: 10.1016/s0002-9343(01)01104-4] [Medline: 11893370]

32. Greene HL. Sudden arrhythmic cardiac death--mechanisms, resuscitation and classification: the Seattle perspective. Am J Cardiol 1990 Jan 16;65(4):4B-12B. [doi: 10.1016/0002-9149(90)91285-e] [Medline: 2404396]

33. Yap YG, Camm AJ. Drug induced QT prolongation and torsades de pointes. Heart 2003 Nov;89(11):1363-1372. [doi: $\underline{10.1136 / \text { heart.89.11.1363] [Medline: 14594906] }}$

34. Lazzara R. Antiarrhythmic drugs and torsade de pointes. Eur Heart J 1993 Nov;14(Suppl H):88-92. [doi: 10.1093/eurheartj/14.suppl_h.88] [Medline: 8293758]

35. Chugh SS, Reinier K, Teodorescu C, Evanado A, Kehr E, Al Samara M, et al. Epidemiology of sudden cardiac death: clinical and research implications. Prog Cardiovasc Dis 2008;51(3):213-228 [FREE Full text] [doi:

10.1016/j.pcad.2008.06.003] [Medline: 19026856]

36. Chugh SS, Jui J, Gunson K, Stecker EC, John BT, Thompson B, et al. Current burden of sudden cardiac death: multiple source surveillance versus retrospective death certificate-based review in a large US community. J Am Coll Cardiol 2004 Sep 15;44(6):1268-1275 [FREE Full text] [doi: 10.1016/j.jacc.2004.06.029] [Medline: 15364331]

37. Stecker EC, Reinier K, Marijon E, Narayanan K, Teodorescu C, Uy-Evanado A, et al. Public health burden of sudden cardiac death in the United States. Circ Arrhythm Electrophysiol 2014 Apr;7(2):212-217 [FREE Full text] [doi: 10.1161/CIRCEP.113.001034] [Medline: 24610738]

38. Electronic Code of Federal Regulations: Title 45: Subtitle A, Subchapter C, Part 160. URL: https://www.ecfr.gov/cgi-bin/ text-idx?tpl=/ecfrbrowse/Title45/\%2045cfr160 main 02.tpl [accessed 2018-04-18]

39. Federal Policy for the Protection of Human Subjects ('Common Rule'). Office for Human Research Protections. URL: https://www.hhs.gov/ohrp/ [accessed 2017-06-22]

40. Federalwide Assurance (FWA) for the Protection of Human Subjects: 45 CFR 46. Office for Human Research Protection. URL: https://www.hhs.gov/ohrp/register-irbs-and-obtain-fwas/fwas/fwa-protection-of-human-subjecct/index.html [accessed 2020-07-31]

41. Criteria To Be Applied In Approving National Death Index Applications. Centers for Disease Control and Prevention. 2017. URL: https://www.cdc.gov/nchs/data/ndi/ndi_approval_criteria.pdf [accessed 2018-04-13]

42. National death Index: User's Guide. Centers for Disease Control and Prevention. 2019. URL: https://www.cdc.gov/nchs/ data/ndi/ndi users guide.pdf [accessed 2019-06-06]

43. Zheng ZJ, Croft JB, Giles WH, Mensah GA. Sudden cardiac death in the United States, 1989 to 1998. Circulation 2001 Oct 30;104(18):2158-2163. [doi: 10.1161/hc4301.098254] [Medline: 11684624] 
44. Carnes C. Antiarrhythmic drug classification. In: Billman GE, editor. Novel Therapeutic Targets for Antiarrhythmic Drugs. Hoboken, New Jersey: Wiley; 2010:155-170.

45. Campbell TJ, Vaughan Williams EM, editors. Classification of antiarrhythmic actions. In: Antiarrhythmic Drugs. New York, USA: Springer; 1989:45-67.

46. Cohort Identification and Descriptive Analysis (CIDA) Module. Sentinel Initiative. URL: https://dev.sentinelsystem.org/ projects/SENTINEL/repos/sentinel-routine-querying-tool-documentation/browse/files/file118-type02-overlap.md [accessed 2018-04-11]

47. Curtis LH, Weiner MG, Boudreau DM, Cooper WO, Daniel GW, Nair VP, et al. Design considerations, architecture, and use of the mini-sentinel distributed data system. Pharmacoepidemiol Drug Saf 2012 Jan;21(Suppl 1):23-31. [doi: 10.1002/pds.2336] [Medline: 22262590]

48. CDC Wonder. Centers for Disease Control and Prevention. URL: https://wonder.cdc.gov/ [accessed 2020-07-31]

49. Hennessy S, Leonard CE, Freeman CP, Deo R, Newcomb C, Kimmel SE, et al. Validation of diagnostic codes for outpatient-originating sudden cardiac death and ventricular arrhythmia in medicaid and medicare claims data. Pharmacoepidemiol Drug Saf 2010 Jun;19(6):555-562 [FREE Full text] [doi: 10.1002/pds.1869] [Medline: 19844945]

50. Ray WA, Murray KT, Hall K, Arbogast PG, Stein CM. Azithromycin and the risk of cardiovascular death. N Engl J Med 2012 May 17;366(20):1881-1890. [doi: 10.1056/nejmoa1003833] [Medline: 22591294]

51. Hennessy S, Leonard C, Newcomb C, Kimmel S, Bilker W. Cisapride and ventricular arrhythmia. Br J Clin Pharmacol 2008 Sep;66(3):375-385 [FREE Full text] [doi: 10.1111/j.1365-2125.2008.03249.x] [Medline: 18662288]

52. Trac MH, McArthur E, Jandoc R, Dixon SN, Nash DM, Hackam DG, et al. Macrolide antibiotics and the risk of ventricular arrhythmia in older adults. Can Med Assoc J 2016 Apr 19;188(7):E120-E129 [FREE Full text] [doi: 10.1503/cmaj.150901] [Medline: 26903359]

53. Health information policy council. 1984 revision of the Uniform Hospital Discharge Data Set--HHS. Notice. Federal register 1895;50(147):31038-31040. [Medline: 10272121]

54. Faurot KR, Jonsson Funk M, Pate V, Brookhart MA, Patrick A, Hanson LC, et al. Using claims data to predict dependency in activities of daily living as a proxy for frailty. Pharmacoepidemiol Drug Saf 2015 Jan;24(1):59-66 [FREE Full text] [doi: 10.1002/pds.3719] [Medline: 25335470]

55. Leonard CE, Freeman CP, Razzaghi H, Carnahan RM, Chrischilles EA, Andrade SE, et al. Mini-Sentinel Methods: 15 Cohorts of Interest for Surveillance Preparedness. Sentinel Initiative. 2014. URL: https://www.sentinelinitiative.org/sites/ default/files/Methods/Mini-Sentinel Methods 15-Cohorts-of-Interest-for-Surveillance-Preparedness 0.pdf [accessed 2020-07-31]

56. Kannel WB, Schatzkin A. Sudden death: lessons from subsets in population studies. J Am Coll Cardiol 1985 Jun;5(6 Suppl):141B-149B [FREE Full text] [doi: 10.1016/s0735-1097(85)80545-3] [Medline: 3889106]

57. Kucharska-Newton AM, Couper DJ, Pankow JS, Prineas RJ, Rea TD, Sotoodehnia N, et al. Diabetes and the risk of sudden cardiac death, the atherosclerosis risk in communities study. Acta Diabetol 2010 Dec;47(Suppl 1):161-168 [FREE Full text] [doi: 10.1007/s00592-009-0157-9] [Medline: 19855920]

58. Vasiliadis I, Kolovou G, Mavrogeni S, Nair D, Mikhailidis D. Sudden cardiac death and diabetes mellitus. J Diabetes Complications 2014;28(4):573-579. [doi: 10.1016/j.jdiacomp.2014.02.003] [Medline: 24666923]

59. Kannel WB, Plehn JF, Cupples LA. Cardiac failure and sudden death in the Framingham study. Am Heart J 1988 Apr;115(4):869-875. [doi: 10.1016/0002-8703(88)90891-5] [Medline: 3354416]

60. Toh D, Reichman ME, Houstoun M, Ross Southworth M, Ding X, Hernandez A, et al. Mini-Sentinel Medical Product Assessment: Signal Refinement of Angioedema Events in Association With Use of Drugs That Act on the Renin-Angiotensin-Aldosterone System Report. Sentinel Initiative. 2012. URL: https://www.sentinelinitiative.org/sites/ default/files/Drugs/Assessments/Mini-Sentinel_Angioedema-and-RAAS_Final-Report.pdf [accessed 2020-07-31]

61. Pun PH, Smarz TR, Honeycutt EF, Shaw LK, Al-Khatib SM, Middleton JP. Chronic kidney disease is associated with increased risk of sudden cardiac death among patients with coronary artery disease. Kidney Int 2009 Sep;76(6):652-658 [FREE Full text] [doi: 10.1038/ki.2009.219] [Medline: 19536082]

62. Shamseddin MK, Parfrey PS. Sudden cardiac death in chronic kidney disease: epidemiology and prevention. Nat Rev Nephrol 2011 Mar;7(3):145-154. [doi: 10.1038/nrneph.2010.191] [Medline: 21283136]

63. Quan H, Li B, Saunders LD, Parsons GA, Nilsson CI, Alibhai A, et al. Assessing validity of ICD-9-CM and ICD-10 administrative data in recording clinical conditions in a unique dually coded database. Health Serv Res 2008 Aug;43(4):1424-1441 [FREE Full text] [doi: 10.1111/j.1475-6773.2007.00822.x] [Medline: 18756617]

64. Becker LB, Han BH, Meyer PM, Wright FA, Rhodes KV, Smith DW, et al. Racial differences in the incidence of cardiac arrest and subsequent survival. The CPR Chicago project. N Engl J Med 1993 Aug 26;329(9):600-606. [doi: 10.1056/NEJM199308263290902] [Medline: 8341333]

65. Friede A, Reid JA, Ory HW. CDC wonder: a comprehensive on-line public health information system of the centers for disease control and prevention. Am J Public Health 1993 Sep;83(9):1289-1294. [doi: 10.2105/ajph.83.9.1289] [Medline: $\underline{8395776}]$

66. Deo R, Albert CM. Epidemiology and genetics of sudden cardiac death. Circulation 2012 Jan 31;125(4):620-637 [FREE Full text] [doi: 10.1161/CIRCULATIONAHA.111.023838] [Medline: 22294707] 
67. Straus S, Bleumink G, Dieleman J, van der Lei J, Stricker B, Sturkenboom M. The incidence of sudden cardiac death in the general population. J Clin Epidemiol 2004 Jan;57(1):98-102. [doi: 10.1016/S0895-4356(03)00210-5] [Medline: 15019016]

68. Kannel WB, Wilson PW, D'Agostino RB, Cobb J. Sudden coronary death in women. Am Heart J 1998 Aug;136(2):205-212. [doi: 10.1053/hj.1998.v136.90226] [Medline: 9704680]

69. Goraya TY, Jacobsen SJ, Kottke TE, Frye RL, Weston SA, Roger VL. Coronary heart disease death and sudden cardiac death: a 20-year population-based study. Am J Epidemiol 2003 May 1;157(9):763-770. [doi: 10.1093/aje/kwg057] [Medline: 12727669]

70. Zipes DP, Wellens HJ. Sudden cardiac death. Circulation 1998 Nov 24;98(21):2334-2351. [doi: 10.1161/01.cir.98.21.2334] [Medline: 9826323 ]

71. Fox CS, Evans JC, Larson MG, Kannel WB, Levy D. Temporal trends in coronary heart disease mortality and sudden cardiac death from 1950 to 1999: the Framingham Heart Study. Circulation 2004;110:522-527. [doi:

10.1161/01.cir.0000136993.34344.41]

72. Albert CM, Chae CU, Grodstein F, Rose LM, Rexrode KM, Ruskin JN, et al. Prospective study of sudden cardiac death among women in the United States. Circulation 2003 Apr 29;107(16):2096-2101. [doi: 10.1161/01.CIR.0000065223.21530.11] [Medline: 12695299]

73. Jouven X, Desnos M, Guerot C, Ducimetière P. Predicting sudden death in the population: the Paris prospective study I. Circulation 1999 Apr 20;99(15):1978-1983. [doi: 10.1161/01.cir.99.15.1978] [Medline: 10209001]

74. Jouven X, Lemaître RN, Rea T, Sotoodehnia N, Empana J, Siscovick D. Diabetes, glucose level, and risk of sudden cardiac death. Eur Heart J 2005 Oct;26(20):2142-2147. [doi: 10.1093/eurheartj/ehi376] [Medline: 15980034]

75. Leonard CE, Brensinger CM, Aquilante CL, Bilker WB, Boudreau DM, Deo R, et al. Comparative safety of sulfonylureas and the risk of sudden cardiac arrest and ventricular arrhythmia. Diabetes Care 2018 Apr;41(4):713-722 [FREE Full text] [doi: 10.2337/dc17-0294] [Medline: 29437823]

\author{
Abbreviations \\ FAERS: FDA Adverse Event Reporting System \\ FDA: United States Food and Drug Administration \\ FWA: Federalwide Assurance \\ HPHCI: Harvard Pilgrim Health Care Institute \\ ICD-9: International Classification of Diseases, 9th Revision \\ ICD-10: International Classification of Diseases, 10th Revision \\ IRB: institutional review board \\ NCHS: National Center for Health Statistics \\ NDI: National Death Index \\ NDI+: National Death Index Plus \\ SCD: sudden cardiac death \\ SSA: Social Security Administration
}

Edited by G Eysenbach; submitted 29.06.20; peer-reviewed by N Mohammad Gholi Mezerji, G Luo; comments to author 22.07.20;
revised version received 04.08.20; accepted 11.08.20; published 02.11.20
Please cite as:
Fuller CC, Hu W, Leonard CE, Mosholder A, Carnahan R, Dutcher S, King K, Petrone AB, Rosofsky R, Shockro LA, Young J, Min
JY, Binswanger I, Boudreau D, Griffin MR, Adgent MA, Kuntz J, McMahill-Walraven C, Pawloski PA, Ball R, Toh S
Developing a Standardized and Reusable Method to Link Distributed Health Plan Databases to the National Death Index: Methods
Development Study Protocol
JMIR Res Protoc $2020 ; 9(11): e 21811$
URL: https://www.researchprotocols.org/2020/11/e21811
doi: $\underline{10.2196 / 21811}$
PMID: $\underline{3136063}$

(C) Candace C Fuller, Wei Hua, Charles E Leonard, Andrew Mosholder, Ryan Carnahan, Sarah Dutcher, Katelyn King, Andrew B Petrone, Robert Rosofsky, Laura A Shockro, Jessica Young, Jea Young Min, Ingrid Binswanger, Denise Boudreau, Marie R Griffin, Margaret A Adgent, Jennifer Kuntz, Cheryl McMahill-Walraven, Pamala A Pawloski, Robert Ball, Sengwee Toh. Originally published in JMIR Research Protocols (http://www.researchprotocols.org), 02.11.2020. This is an open-access article distributed under the terms of the Creative Commons Attribution License (https://creativecommons.org/licenses/by/4.0/), which permits unrestricted use, distribution, and reproduction in any medium, provided the original work, first published in JMIR 
Research Protocols, is properly cited. The complete bibliographic information, a link to the original publication on http://www.researchprotocols.org, as well as this copyright and license information must be included. 